\title{
Doctors in management: Three doctors' experiences
}

\author{
ROBERT HARDWICK, JOHN DE BENE, ALAN BUSSEY
}

About one in seven general management posts are filled by doctors at regional, district, and unit level in England and Wales. In Maidstone three doctors have been appointed, each from a different professional background. We asked them for their experiences and reflections on their first months in office.

\section{The consultant's tale}

Towards the end of my clinical career I have suddenly found myself the part time unit general manager of a unit responsible for acute services and services for the elderly and physically handicapped. How did it happen?

I have always had an interest in hospital management; I was a member of the local hospital management committee and after the 1974 reorganisation found myself the consultant representative on the district management team for the next four years.

In 1982, with the formation of the district health authority, I became the consultant member on the authority. When the Griffiths structure was being talked about I thought it essential that the medical profession should participate and started to persuade my colleagues to apply for the unit general management posts. It was with genuine surprise that I found myself being persuaded to apply for the job.

I have been in post for almost 18 months and am beginning to see how it is possible to be a part time clinician (five sessions a week) and a part time manager (five sessions a week), managing a $£ 17$ million budget and with responsibility for the district general hospital, an ear, nose, and throat and eye hospital, some continuing care beds for the elderly, and the associated community services.

From the outset I realised that it would be essential to have a good deputy and to divide the unit into definite and identifiable sections, each with its own manager. In this way I could be shielded from the hour to hour, day to day problems and be left with time for the major issues. I also realised that a large amount of time would be taken up with the inevitable meetings necessary to liaise with the rest of the units, the district general manager, and the district health authority.

Here I met the first problem. While everyone agreed on the necessity of a strong deputy it seemed that it was not possible to get a grading for this post that would suit the calibre of person required. In the end the right person was appointed, but this is an area that needs to be kept under review so that a person of sufficient calibre to support a medical unit manager may be attracted to this post when the existing incumbent moves on.

For many years the unit has functioned on four separate sites, with obvious revenue consequences. So a plan to reduce to three sites immediately, to two within four to five years, and to one within the decade was worked out. After some discussion this was agreed with the clinicians, but agreement could not be reached with the community health council (CHC), which opposed parts of the plan. The negotiations and the procedures that had to be followed to try to get this deal through were a fascinating example of the way that the National Health Service works. As a result of $\mathrm{CHC}$ opposition these potential economies have been delayed and the

Maidstone Health Authority, Preston Hall, Maidstone, Kent ME20 7AJ ROBERT HARDWICK, FRCP, FRCGP, consultant physician

JOHN DE BENE, MB, CHB, general practitioner

ALAN BUSSEY, MRCGP, FFCM, district general manager

Correspondence to: Dr Bussey. necessary additional consultant appointments on which the money would have been spent have had to be postponed.

There is a continuing problem of finance and financial control. The unit seems to be overspending. I have had the greatest difficulty in getting sufficiently accurate figures fast enough to achieve tight financial control. If sensible and sensitive financial control is to be achieved I am convinced that each unit must have its own management accountant responsible to the unit and not just to the finance department. This has now been agreed and the post has recently been filled. In discussion with my clinical colleagues it is obvious that they appreciate that funds are limited and that money spent on one thing cannot later be spent on another. Accurate simply laid out financial information would win their cooperation.

Apart from this I have not run into any major hazards, and after almost 18 months the unit is beginning to weld into a team and the great majority of the year's objectives have been achieved.

My background as a consultant physician has been helpful. It has meant that I have been able to discuss matters easily and informally with all my consultant colleagues and several issues have been solved which, without this informal approach, could have worsened. It has also meant that when I have had to say "no" it has been appreciated that the clinical consequences have been understood as well as the management ones; this has helped my clinical colleagues to accept the decision. The fact that I have worked in the district for more than 25 years has also helped as I have known and been able to talk to many of the staff as a clinician with management interests.

Doctors must be prepared to take up their share of management responsibilities if the best and smoothest running health service is to be developed. I am concerned that my colleagues do not appreciate this and that in the future there may not be a sufficiently powerful medical input into management.

On the whole I enjoy my job. I think that I have been able to simplify the chain of command and to give people definite areas of responsibility within which they are the "boss." This not only gives the managers job satisfaction but is also satisfying to those managed as they see a person who is in charge and who has the power and ability to deal with their day to day problems.

I am also concerned in the further development of the district general hospital-another major building phase is planned over the next five years-and am able to initiate plans for building links between the hospital and a teaching hospital which will include medical students to consultants. It is all very exciting.ROBERT HARDWICK.

\section{The general practitioner's tale}

I have been a general practitioner for 15 years. For the first ten years I was totally absorbed in my practice, learning the trade, developing the surgery, becoming a trainer, and so on. At the end of that time I began to realise that I was working in a cocoon, that there were many other aspects to health care, and, most importantly, that decisions were being made at various levels in the NHS that had a profound effect on me and on my patients. Some of these decisions were difficult to understand and often did not seem particularly sensible to me as a reasonably experienced practitioner. I also realised that by listening to my patients I was well informed about the good and bad aspects of health care in the district.

My curiosity pushed me into examining how decisions were made and how those in power were advised by the professionals. I soon realised that in many cases they were not advised, mainly because of the medical profession's apathy. One respected colleague told me 
that administrators were there to make these decisions and that we should simply let them get on with it. I tried to argue that someone sitting in an office was not always the best placed to know the health needs of a population; to do their jobs properly administrators were desperately in need of advice from all who worked the system.

Soon discovering that the real power base in my district was the district management team, I set about getting on to it. I became chairman of the district's general practitioner council, which gave me a seat on the team. It was fascinating to see how it all workedthe power struggles, the games, and the politics necessary to get decisions made-but I became frustrated at the lack of sharpness. Because of the multifaceted nature of such a team consensus management was necessary for the team to survive. When consensus was not possible the important, often fundamental, decisions would be shelved.

Just at this time, as my concern about the consensus approach increased, Roy Griffiths published his thoughts on management in the NHS. These centred around the simple question, "Who is in charge?" The concept of having general managers on short term contracts with some financial recognition of their performance, who were in charge of a unit in the NHS and, in the final analysis, were accountable for the performance of that unit, seemed exactly right to me. My excitement grew when I realised that general managers could come from any discipline so long as they were able to display the required managerial skills. So I applied, was interviewed in competition with others, and found myself appointed part time unit general manager of a unit providing maternity, gynaecological, and paediatric services in both the hospital and community settings.

Why should a general practitioner want to participate in NHS management? A general practitioner is aware of the overall requirements of the district, and he or she has the advantage of an immediate network of consumer advice-advice from all aspects of a community. By listening, and from the experience of day to day practice, the general practitioner comes to know what is good, bad, or deficient in the district's health care provision. By becoming a general manager he has the chance to correct some of these deficiencies.

\section{Doctors must lead the debate}

I have also realised, as have many of my colleagues, that doctors will have to enter the debate about the funding of the health service wherever they practice. Whatever type of society you live in and whatever the colour of the government the resources available for health provision are finite. Medicine today, given sufficient funds, is capable of almost any feat. But can society afford it? Doctors must participate in this debate and, as a doctor in management, I think that I will have a greater chance of bringing my colleagues into the discussion. As professionals we cannot ignore the resource ramifications of what we do. The debate will be difficult and painful, and doctors must lead it. I know that the idea of entering arguments about such concepts as quality adjusted life years is abhorrent to many doctors, but they will have to be faced.

If we are to manage our health service and the limited funds that are available managers will have to draw in clinicians because they are responsible for directing the use of most of these resources. Many clinicians do not wish to join in this part of the debate because they just want to practise their profession in as good an environment as possible and be allowed to get on with it. As a doctor I appreciate this, and one of my main ambitions as a manager is to enable the clinical process to occur in an environment that is as efficient, effective, and caring as possible.

There is an advantage to being a part time manager and part time general practitioner. I have already mentioned the clinical contact with patients and the resultant understanding of their needs. Why a part time manager? He or she has to be organised to survive and there is no time to become an "administrator." You must remain above it all-surely where a manager should be-taking an overall view of the unit and adopting a corporate responsibility for the organisation.

Are there any disadvantages? Yes, some of the decisions will be unpopular and some colleagues will be critical. As a general practitioner having to rely in many instances on the services of my consultant colleagues I feel rather vulnerable at times. There are also certain personal and social disadvantages-finding the time to cope adequately with two responsible careers is at times exhausting and frustrating. Your partners and family occasionally feel deprived and neglected.

In the long run I trust that it will be worth while; if the service to the patient is improved in quality and quantity as a result of my prowess as a manager it will be.-JOHN DE BENE.

\section{The community physician's tale}

Two years as a district general manager have taught me several things. Firstly, general management can be addictive and might usefully have a health warning on it. Secondly, in many respects it is applied community medicine-judging the needs of a population. It means identifying the current pattern of use of money, people, buildings, and equipment (imprecisely lumped together in management jargon as "resources"), and then using the management and political machinery to better match them with the needs. But it is what has to be learnt and what has to be done to achieve that better match that is the real eye opener.

To begin with you stop doing a proper job in one sense. That is to say, instead of personally completing defined chunks of work you spend large parts of your time catalysing and encouraging others to perform to a high standard. I am now convinced that top managers should be good gardeners because a major part of their job is to dung and water in order to create an environment in which things can grow. There is no better description of management than "getting things done through people," and if the people in your district (be they doctors, nurses, managers, or other staff) can grow professionally and personally your job is made easier. Surgeons know this to be true of their theatre team and so do general practitioners of the practice team. It is no different in management.

Some of what has to be learnt comes from the hard school of experience-forging relationships with the media, for example. A selective use of the management literature and management schools and courses is also helpful. Good management teachers (like their clinical counterparts) base their teaching on the real world, using case studies and the combined experience of managers. But unlike Zen Buddhism or yoga there is no great mystique in managementmore of it is common sense than some management schools or consultancy firms would like to admit. It is essentially about weighing information and juggling probabilities in trying to resolve problems and take decisions - a process wholly familiar to clinicians.

Indeed, management consultants hijacked the diagnostic process for their own purposes long ago. They may dress up what they do in different jargon but, in essence, when called in to an organisation with a problem they take a history, conduct an examination, supplement that with selective investigations, come to a tentative diagnosis, and then propose a treatment plan. It could be argued, therefore, that medical training is a better grounding for management than almost any other.

And the similarities with medical practice do not end there. The aims of health service management are, or should be, the sameimproved patient care (quantity and quality) and, where possible, reduced incidence of disease. I know that there are occasions when clinicians seriously doubt this coincidence of aims. The doubts usually arise when someone says "no" and blames the cash limits, or when an apparently irrelevant and costly initiative is taken. But computerised Körner information systems and workload related budgets are not irrelevant. They are essential tools if we are to modernise the management of the NHS to keep pace with the changes in medicine.

Good management and good medicine are not incompatible but complementary. Both sides-because there are still "sides"-need to recognise this and work to narrow the gap between them. Two years' experience has confirmed my belief that doctors in management have a unique contribution to make.-ALAN BUSSEY. 


\section{GMC to review disciplinary procedures}

The General Medical Council is to review its procedures for dealing with doctors who seriously neglect or disregard their professional responsibilities to patients. Sir John Walton, the president, will chair a working party, agreed by the council at its May meeting, which will consist of medical and lay members.

There have been attempts in the past, notably by the Labour MP, Mr Nigel Spearing, to amend the 1983 Medical Act so that the professional conduct committee is empowered to impose conditions on the registration of a doctor who has been judged not guilty of serious professional misconduct but guilty of a lesser offence of unacceptable professional conduct. The council has maintained that it would be difficult to draw a distinction between unacceptable conduct and serious professional misconduct. In 1984, however, the council did agree to amend its guidance on the general duty of professional care, and the following section was added:

"The public are entitled to expect that a registered medical practitioner will afford and maintain a good standard of medical care. This includes:

"( $a$ ) conscientious assessment of the history, symptoms, and signs of a patient's condition;

" $(b)$ sufficiently thorough professional attention, examination, and, where necessary, diagnostic investigation;

" $(c)$ competent and considerate professional management;

“(d) appropriate and prompt action upon evidence suggesting the existence of a condition requiring urgent medical intervention; and

" $(e)$ readiness, where the circumstances so warrant, to consult appropriate professiona colleagues.

"A comparable standard of practice is to be expected from medical practitioners whose contribution to a patient's care is indirect-for example, those in laboratory and radiological specialties."

At its meeting last month the GMC was told that the numbers of cases of alleged disregard of professional responsibilities referred to the preliminary proceedings committee had risen from 26 in 1983 to 59 in 1986 and that a substantially larger proportion of such cases had been referred for inquiry by the professional conduct committee. Of these 23 cases, 13 were found not guilty of serious professional misconduct.

\section{No change in guidance on treating under 16s}

A year ago the GMC reaffirmed its guidance on giving advice and treatment on pregnancy and contraception to the under 16s. The BMA had asked the council to make it clear that the right of young people to consult a doctor in confidence had not been changed in any way. There was concern at the following paragraph in the GMC's guidance:

"If the doctor is not so satisfied [of the child's maturity and ability to understand] he may decide to disclose the information learned from the consultation; but if he does so he should inform the patient accordingly, and his judgment concerning disclosure must always reflect both the patient's best medical interest and the trust the patient places in the doctor."

The president, Sir John Walton, will continue to undertake the preliminary screening of conduct cases and health cases, and he has nominated Dr John Fry (conduct) and Dr P $\mathbf{H}$ Connell (health) to continue to help with the screening of new cases. Sir John has reappointed $\mathrm{Mr}$ David Bolt as chairman and Professor H L Duthie as deputy chairman of the professional conduct committee. Professor Sir Robert Kilpatrick and Dr Anthony Allibone have been reappointed chairman and deputy chairman of the health committee.

The BMA had again asked the council to reconsider its guidance in the light of a resolution passed at the 1986 annual representative meeting: " $(a)$ That those children under 16 must be entitled to expect that both the existence and content of a consultation in connection with pregnancy or contraception will normally remain secret; $(b)$ that in the case of any departure from this rule doctors should be liable to justify their action."

Last month the chairman of the standards committee, Dr Donald Irvine, told the council that only four letters from individuals had been received on the subject. The council, therefore, endorsed the committee's recommendation that the guidance should not be altered bearing in mind that it states that "whatever the circumstances, a doctor must always be prepared to justify his action if he has disclosed confidential information."

\section{GMSC meets in Edinburgh}

The General Medical Services Committee met in Edinburgh on 21 May with Dr Michael Wilson in the chair.

A working party has been set up to assess the proposals from companies to provide computer systems to general practitioners free of charge. This assessment will be done as a matter of urgency so that guidance may be given to general practitioners. In the mean time local medical committees have been reminded of the following guidance on confidentiality and market research: "Any information leaving a practice for market research should be checked for confidentiality by the doctor before being handed over. If this information is to be sent on a tape or floppy disc then the doctor should be able to display that information, either on his VDU or by printing out the data into a readable and understandable form. Such a check should be carried out on each occasion that information leaves the practice. The company that supplies the programme should ensure that the general practitioner is instructed on how to carry out this confidential check."

\section{Original pack dispensing}

The committee has agreed that there should be a joint approach with the pharmaceutical industry, the pharmaceutical profession, and the Department of Health to implement original pack $\overrightarrow{\vec{F}}$ dispensing. The GMSC has been urging the department to release a report on the subject produced a year ago. Dr Wilson said that he thought that the department was stalling though it was believed that the experts had recommended a single 28 unit pack size. This is also the recommendation of the Pharmaceutical Society of Great Britain, and the GMSC has added its weight to this solution. The $\vec{O}$ industry, however, for reasons of cost, space, and packaging arrangements supports pack sizes of $28 \omega$ or 30 days' treatment. The committee adopted the following recommendations in a discussion paper prepared by the chairman:

(i) Pack sizes should be standardised.

(ii) The pack size for short courses of treatment should be seven units.

(iii) The pack size for maintenance or regular reatment should be 28 units.

(iv) The pack sizes for liquid preparations should be $50,100,150,200,300$, or $500 \mathrm{ml}$.

(v) The pack sizes for ointments and creams $O$ should be $5,10,25,50,100,250,500$, or $1000 \mathrm{~g}$. (vi) The pack sizes for drops should be 5 or $10 \mathrm{ml}$.

(vii) The pack size for ear, nose, and eye $\ddot{\emptyset}$ ointment should be $3 \mathrm{~g}$.

(viii) The pack size for aerosol inhalers should be 200 metered dose units.

(ix) Controlled drugs should continue to be dispensed in the exact quantity prescribed.

$(x)$ Doctors should be encouraged to prescribe quantities in accordance with pack size recommendations.

(xi) The GMSC should endeavour to secure a joint approach with the industry, the pharmaceutical profession, and the department to the implementation of original pack dispensing.

In receiving the 17th report of the review body the committee was concerned about the scant mention of the workload survey, the decision not to increase the trainers' grant, and the payment of a differential award to hospital and community doctors. The negotiators will pursue these issues when preparing evidence for the next review.

There were no objections to proposals to intro- N duce a new form (to come into use in July) for $\supset$ doctors to use when notifying the chief medical officer of known or suspected drug addicts. The form will also be used to collect data on the numbers of notified addicts who inject any illicit drug as part of the strategy to combat the spread of the human immunodeficiency virus.

The committee will join a small group with the department to look at the provision of medical care in nursing homes.

Along with the Doctors' Wives Association the negotiators have again discussed proposals with the department for including relatives in $O$ the ancillary staff scheme. Progress is still being blocked by the department's insistence that any revision of the scheme must be at no additional cost.

Published by the Proprietors, THE BRITISH MEDICAL ASSOCIATION, Tavistock Square, London WC1H 9JR, and printed in Great Britain by Pulman Web Offset Limited, Member of BPCC Group. Typesetting by Bedford Typesetters Limited, Bedford. 